\title{
Diálogos: una oportunidad para la paz
}

DIALOGUES: AN OPPORTUNITY FOR PEACE

DIÁLOGOS: UMA OPORTUNIDADE PARA A PAZ

\section{Luis Guillermo Guerrero Guevara* / direccion@Cinep.org.co}

\section{Resumen}

El presente artículo tiene como propósito presentar un análisis de los procesos de paz que se realizan en La Habana, Cuba, reflexionando sobre los diferentes aspectos que hacen parte del presente nacional; para hacerlo, se exponen 10 puntos importantes a la hora de enfrentar la actualidad de los acuerdos de paz. Al tiempo, estos puntos justifican el diálogo como el proceso más apropiado para la concreción de un cierre definitivo del conflicto armado entre las FARC y el Estado, todo, considerando el papel de la educación como herramienta indispensable en el fortalecimiento de una cultura de paz.

\section{Summary}

This article aims to present an analysis of peace processes that take place in Havana, Cuba, reflecting on the different aspects that are part of this country, to do this 10 important points are set when face today of the peace accords. While these points justify the dialogue as the most suitable for the realization of a permanent closure of the armed conflict between the FARC and the state process, especially considering the role of education as an indispensable tool in building a culture of peace.

\section{Resumo}

O presente artigo tem como propósito apresentar uma análise dos processos de paz que se realizam em Havana, Cuba, reflexionando sobre os diferentes aspectos que fazem parte do presente nacional; para fazê-lo, expõem-se 10 pontos importantes à hora de enfrentar a actualidade dos acordos de paz. Ao tempo, estes pontos justifica o diálogo como o processo mais apropriado para a concreción de um fechamento definitivo do conflito armado entre as FARC e o Estado, tudo, considerando o papel da educação como ferramenta indispensável no fortalecimento de uma cultura de paz.
Palabras clave

Diálogos de paz 2013, FARC, conflicto armado, acuerdos, condiciones para la paz.

\section{Keywords}

2013 peace negotiations, FARC, armed conflict, agreements, conditions for peace.

\section{Palavras chave}

Diálogos de paz 2013, FARC, conflito armado, acordos, condições para a paz.

* Director General CINEP/ Programa por la Paz. 
Después de 50 años de conflicto armado, tres generaciones de colombianos y colombianas desearían expresar a todo pulmón: "De la Habana viene un barco cargado de PAZ".

Sin embargo, y a pesar de los avances en la agenda, los resultados del diálogo son aún inciertos. Nadie se arriesga todavía, luego de cerca de una año de la firma de la agenda, a expresar cuáles podrán ser sus efectos y consecuencias finales. Existen posiciones diversas frente al proceso, algunos plantean un moderado optimismo, otros sectores están esperando el fracaso para arremeter con nuevos Ilamados guerreristas, mientras que algunos hablan de ir midiendo cada paso en medio de las incertidumbres para dejar que el mismo proceso se vaya autoconstruyendo.

Pero, ¿cuál es el contenido de la paz que se está conversando entre el Gobierno y las Farc-EP?, y, por otra parte, ¿qué estamos entendiendo en el país acerca de la paz que se está dialogando en la Habana? Plantearse estas preguntas permitirá, posiblemente, comprender los alcances de los diálogos y dar una dimensión razonable a la paz que se perfila en la isla Caribe.

Una primera consideración es que, sin duda alguna, el diálogo entre el Gobierno y las FARC-EP es un factor necesario y determinante para la solución esencial del conflicto armado, pero esto no quiere decir que agote todo el proceso que necesita recorrer la sociedad colombiana para construir la anhelada paz, integral, sostenible y duradera.

En segundo lugar, la delimitación del proceso de la Habana está definida por la agenda que establecieron las partes en el Acuerdo general para la terminación del conflicto y la construcción de una paz estable y duradera, firmado el miércoles 29 de agosto de 2012. Son cinco temas para discutir: Política de desarrollo agrario integral; Participación política; Fin del conflicto y justicia transicional; Solución al problema de las drogas ilícitas; Y situación de las Víctimas del conflicto armado. Esta es una agenda, que, comparada con la propuesta en el Caguán hace 14 años, aparece mucho más acotada, más realista y responde tanto a las necesidades de los actores que dialogan en esta primera fase del proceso, como a otros actores que en su momento deberán entrar en el camino de la construcción de la paz.
En tercer lugar, se debe tener en cuenta que, si bien el Gobierno y las FARC-EP han mostrado tener voluntad política para llegar a acuerdos, eso no basta para acuñar esa paz, sino que se necesitan, además, condiciones sociales, económicas y políticas que no dependen de ellos, y para las cuales existe un alto déficit que puede llegar a ser uno de los mayores obstáculos.

En cuarto lugar, como dice el profesor Alejo Vargas, necesitamos desmitificar algunas ideas que existen alrededor de las negociaciones. No se puede suponer que las guerrillas, debido a su debilitamiento militar y aislamiento político, estarían dispuestas a negociar su rápida desmovilización. Nada más lejos de la realidad. Las palabras de Iván Márquez fueron claras en su discurso de Oslo: "tanto el Gobierno como las FARC-EP tienen posiciones fuertes y conocen sus límites". La Paz no es un discurso ni una mercancía que se compra y se vende; es, sobre todo, un proceso que requiere imaginación, paciencia, reconocimiento mutuo y renuncia a posiciones polarizadas, para llegar a consensos donde ambas partes cedan algo por el mayor bien de toda la colectividad. De otra manera, no sería un diálogo para construir acuerdos de paz, sino, una capitulación de las FARC-EP o del Gobierno. Y ambas son una quimera, porque la guerrilla no se siente derrotada y el Gobierno se siente vencedor.

La paz tampoco será producto de una negociación corta, o como dicen las Farc-EP, de una paz "exprés". Si bien el proceso no puede ser indefinido ni se pueden establecer tiempos judiciales, las conversaciones deben tener resultados en un período razonable. Si no se van dando esos resultados substanciales paso a paso, y si la opinión pública no los va reconociendo en su imaginario de paz, el proceso va a caer en el agujero negro de la ilegitimidad y la incredulidad, lo que sería nefasto para el diálogo.

Se especula con las posiciones duras, militaristas, y las blandas, de tinte más político, en los negociadores de la guerrilla. Esta apreciación tiene rasgos de ficción. Las FARC-EP son una organización jerárquica, con línea de mando clara y cohesionada en sus posiciones de cúpula en lo sustancial; por lo tanto, sus negociadores van a actuar en consecuencia con este esquema organizacional. Esto mismo sucederá, guardadas las debidas proporciones, con los representantes del gobierno, de 
los empresarios y, más aún, con los dos generales del Ejército y de la Policía que están sentados en la mesa. Existe entonces, en las partes, unidad de pensamiento alrededor de las tesis que cada lado está defendiendo. La cohesión al interior de los equipos está asegurada, lo que política y metodológicamente puede facilitar el diálogo.

En quinto lugar, la paz necesita ser construida entre todos, pero cada uno de los actores debe prestar su colaboración y su servicio pertinente en el momento oportuno. Es irreal creer que la paz se pueda construir sin participación social, pero también es improcedente postular que todos los actores Ilenen la mesa en esta primera fase de la construcción de acuerdos políticos, donde el gobierno y las FARC-EP deben abrir la puerta del diálogo de paz, construir acuerdos y crear las condiciones para honrarlos. A la sociedad civil en toda su amplitud, así como al Congreso de la República, les espera más temprano que tarde, si se firma algún acuerdo, un gran trabajo en el diseño y la realización de procesos, mecanismos y condiciones para la construcción de la paz.

En esta perspectiva, la incidencia de la sociedad civil en la primera fase del diálogo debe ser activa, pero limitada a los escenarios de consulta entre diferentes sectores sociales y con análisis profundos; de igual manera, se les debe dar reconocida importancia a los canales institucionales a través de los cuales estos sectores se pronuncien. De esta forma, en la mesa de La Habana, es pertinente que el Gobierno y las FARC-EP sean los protagonistas para construir lo que les corresponde y con la responsabilidad histórica que esto implica. Ahora, como el proceso de conversaciones no es a espaldas ni a escondidas del país, los colombianos nos debemos enterar sobre los resultados de esta fase del proceso por los canales oficiales definidos por las partes, y no por el show mediático nacional e internacional, por lo cual los medios de comunicación tendrán que actuar con responsabilidad y cautela.

En sexto lugar, por decirlo de manera pedagógica: necesitamos alfabetizar nuestra cultura política, esto es clave para la paz. En Colombia existe una fuerte tendencia a rechazar la política por percibirla como una actividad denigrante, corrupta y deshonesta. Si bien algunos impugnan que esto sea una verdadera política, los hechos confirman que este tipo de práctica es la que con mayor frecuencia vivimos en nuestras veredas, barrios, municipios, regiones y en las instancias públicas del país.

Las costumbres políticas actuales han Ilevado a distintas representaciones de lo político: una primera nos muestra que un amplio sector ciudadano se ha despolitizado $y$, en consecuencia, rechaza y/o es indiferente a la participación en lo público; incluso en menoscabo de sus propios intereses. Estos ciudadanos finalmente buscan diversos caminos para cuidar sus beneficios y promueven un individualismo aislado del "sálvese quien pueda y cómo pueda". En una segunda representación, otros ciudadanos optan por vivir aliados o al lado de los políticos de profesión de todas las tendencias; aprovechan, conviven y cohonestan con una ética de "múltiples cabezas", para alcanzar junto al político corrupto y por todos los medios, incluidos los ilegales y armados, los beneficios e intereses particulares. Finalmente, una tercera representación, muestra sectores ciudadanos y políticos alimentados por movimientos sociales y diversos actores de la sociedad como la academia, la empresa, las iglesias, las organizaciones de mujeres, de jóvenes, gremios, etnias, procesos de nuevas ciudadanías y programas regionales de desarrollo y paz, etc., que vienen replanteando y buscando un nuevo sentido de lo público, del quehacer y de la ética política. Si bien es un proceso nuevo y en etapa de crecimiento en el país, no se puede desconocer que también existe como una propuesta que cobra relevancia en distintas regiones y en el escenario nacional.

Sin lugar a dudas en Colombia necesitamos hacer pedagogía política a favor de esta tercera representación de lo político, para que tengamos la posibilidad de practicar y comprender la política con otros sentidos, paradigmas y resultados. Podemos decir que precisamos de una alfabetización de nuestra vieja y habitual cultura política, esto con mayor obligación en estos tiempos en los que buscamos la superación del conflicto armado por medio del diálogo, para así iniciar el camino hacia una construcción participativa de la paz con justicia, con reconocimiento de las diversidades regionales y culturales, una paz que se hace sostenible no sólo porque somos capaces de llegar a pactar acuerdos y pactos políticos sobre la base de nuestras diferencias, sino porque los principios no se basan en discriminar ni eliminar al contradictor por pensar distinto. 


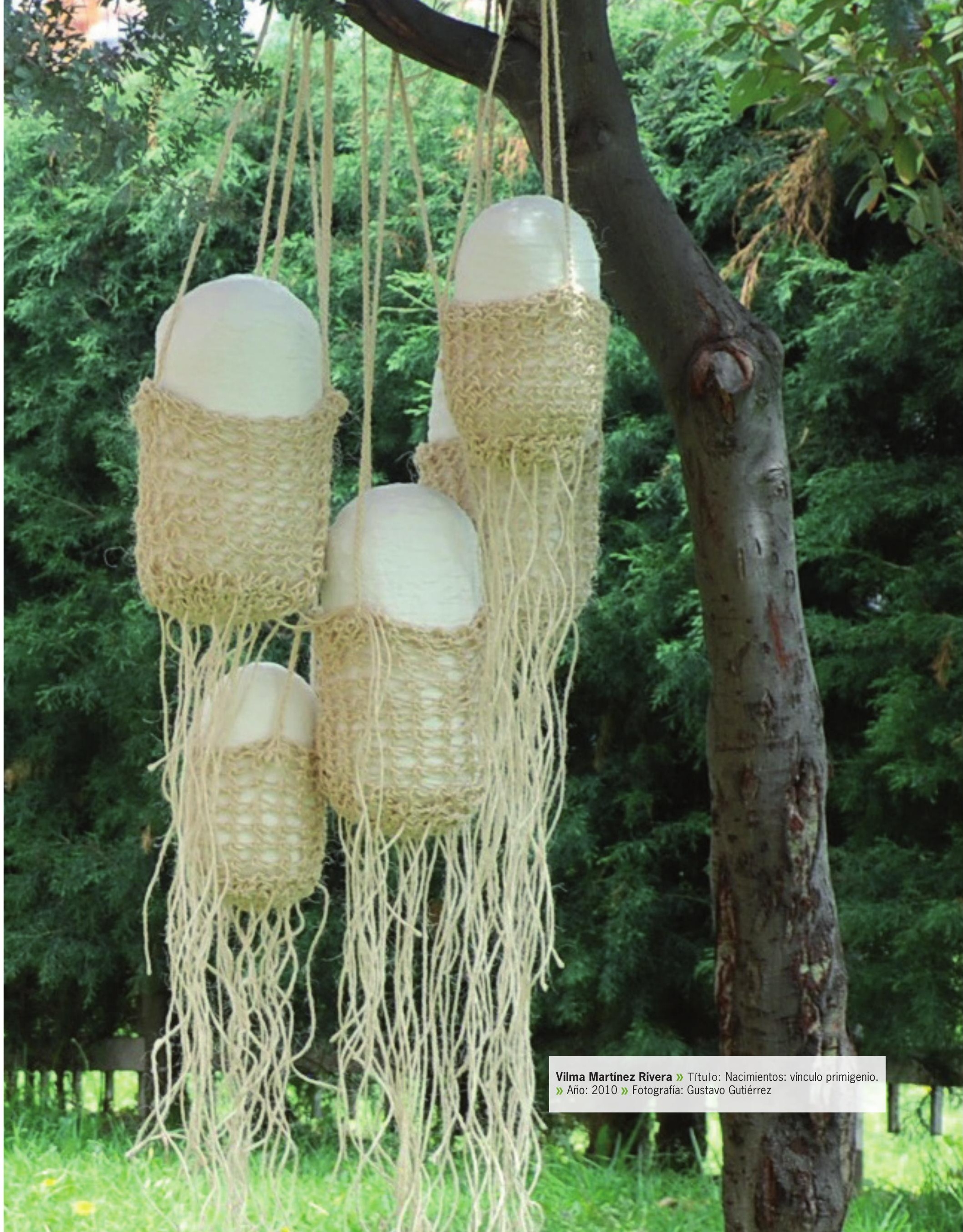


En séptimo lugar, es importante reconocer que escenarios como el de La Habana, enriquecen de manera importante una salida más política que guerrera, tanto para la desactivación y superación del conflicto armado, como para la necesaria y profunda construcción de un proceso de paz en Colombia. No le hacen bien a este proceso ni las posiciones maximalistas ni las minimalistas, tampoco las de una ciudadanía indiferente: la primera, porque le piden al diálogo que supere de la noche a la mañana las causas estructurales del conflicto social y armado, punto de vista que pareciera ignorar el profundo problema que hemos vivido por más de cinco décadas; la segunda posición, minimalista, no le hace bien a los diálogos porque, de manera mordaz y virulenta, sus agitadores califican de insubstancial este diálogo para la paz del país; agregando, a reglón seguido, que este diálogo es otra artimaña de las FARC-EP para tomar oxígeno político y militar, y para el Gobierno del Presidente Santos, una jugada electoral para consolidar su segunda reelección y continuar atado al poder. Por su parte, la posición de indiferencia ciudadana frente a hechos políticos decisivos, como los actuales diálogos de paz, igualmente los erosionan, tanto porque de manera pasiva o activa los invisibiliza, como porque los contamina del virus de la despolitización.

En octavo lugar, resulta importante reconocer que los diálogos de la Habana se ven impactados por los medios de comunicación. Ellos generan opinión, se convierten a sí mismos en los exegetas y en el mecanismo que enseña a la población lo que ocurre en la realidad. Su poder formativo y pedagógico, para mal o para bien, es innegable. Pero no todos los medios son iguales ni responden a los mismos intereses. Los medios escritos contienen información más completa, ponderada y de carácter menos superficial, mientras que la mayoría de los noticieros y programas de opinión en nuestra radio y televisión colombiana, con excepciones contadas y significativas, propenden por mirar los acontecimientos políticos con una mentalidad de telenovela o de película de vaqueros, donde los malos y los buenos están claramente identificados en una confrontación maniquea.

En noveno lugar, la ciudadanía en general debería expresar su apoyo decisivo, constructivo y crítico a las iniciativas de paz, tanto a las que han sido persistentes a través de los años, como a las que se están creando en medio de un clima de esfuerzo entre múltiples actores sociales y públicos, locales, regionales y nacionales. Estos procesos necesitan ser reconocidos, respetados y protegidos, de cara a la consecución de un bien mayor: la paz con justicia social en el país. Esfuerzos que a la vez pueden ser aprovechables para recuperar las lecciones de anteriores acercamientos de paz y para generar nuevos aprendizajes políticos que desarrollen capacidades y aumenten en la sociedad visiones y actitudes que desactiven comprensiones irreconciliables, maniqueas y polarizadas del ejercicio político en el país.

No podemos desperdiciar las oportunidades que se están dando en el camino para dar pasos importantes en la obra de la paz. Muchos estaremos de acuerdo en que para lograrla se necesita ir más allá del silencio de las armas o de los pactos entre cúpulas, y pasar con claridad a la refrendación ciudadana e institucional de los pactos de La Habana, para entrar a la tercera fase de la construcción de una paz integral que, desde la base local y regional, sea políticamente incluyente, socialmente sostenible y éticamente justa.

En décimo lugar, es necesario comprender que no podemos seguir perdiendo las oportunidades históricas y políticas para construir la Paz. "Hay tres cosas que nunca vuelven atrás: la flecha lanzada, la palabra pronunciada y la oportunidad perdida". Desde hace más de cinco décadas los colombianos hemos preferido resolver nuestros problemas sociales con "Ianzar la flecha" para excluir y eliminar al contradictor, en vez de "pronunciar la palabra" para cultivar un diálogo productivo y creativo en medio de las ricas diferencias que tenemos; y por eso mismo hemos "perdido las oportunidades" para construir una nación en paz donde todos podamos vivir dignamente, pero en especial donde las víctimas y los sectores excluidos a los que se les han negado sus oportunidades y violado sus Derechos Humanos tengan posibilidades de vivir en paz.

En conclusión, por estas 10 razones creo que el diálogo, en sus más variadas formas, es el camino; tanto en los "Diálogos de La Habana", para pactar el cierre del conflicto armado entre las FARC y el Estado bajo las condiciones a las que se llegue, como en los diálogos participativos y profundos que debemos realizar los 
colombianos en las diversas instancias de poder y de decisión, desde lo local hasta los escenarios nacionales, para construir una paz desde abajo, una paz desde las localidades y regiones.

Paz con justica social, participativa, sin vencedores ni vencidos y donde exista el monopolio de las armas en las fuerzas del Estado para defender al pueblo. Paz construida desde el reconocimiento mutuo de los contrarios, nacida del acuerdo y de la riqueza de la diversidad de argumentos e intereses en juego, sin trampas, con transparencia, con argumentación, inteligencia y deliberación, para que resulte creativa, estable y duradera. Una paz construida en medio de un complejo tejido dialógico, sin reversa y con el rumbo que le queramos dar los colombianos. Como claramente decía el líder inmolado de la Unión Patriótica en 1990, Bernardo Jaramillo Ossa: "La única salida política al conflicto armado pasa por el diálogo entre gobierno e insurgencia y la interlocución válida de la sociedad civil para encontrar caminos de reconciliación". 